Original Articles

\title{
Plasma Oxygen Permeability May be a Factor in Atherosclerosis
}

\author{
Bradley T. Heppner ${ }^{1}$ and Louis Wm. Morgan² \\ ${ }^{1}$ Chief, Cardiac Catheterization Laboratory, Letterman Army Medical Center, Presidio of San Francisco, CA, USA. \\ ${ }^{2}$ Cardiology Service, Letterman Army Medical Center, Presidio of San Francisco, CA, USA.
}

\begin{abstract}
Plasma oxygen permeability measures how easily oxygen dissolves in and diffuses through blood plasma. There has long been evidence that artery wall hypoxia plays a role in atherogenesis. This paper reviews the influence that plasma oxygen permeability has on artery wall oxygenation and presents experimental evidence for a relationship between plasma oxygen permeability and clinically significant obstructive coronary artery disease. Thirty-eight inpatients referred for diagnostic cardiac catheterization were scored for active coronary artery disease, and their plasma oxygen permeabilities were measured. There was a statistically significant $(p=0.04)$ correlation between active coronary artery disease and plasma oxygen permeability. There were also statistically significant differences in mean plasma oxygen permeability both between patients who did and did not have actively progressing coronary artery disease $(p=0.01)$ and between patients who did and did not have clinically significant obstructive coronary artery disease, whether it was actively progressing or not $(p=$ 0.02). These findings suggest that a decline in plasma oxygen permeability may be one of the many factors associated with progression of atherosclerosis and that substances which increase oxygen permeability might offer a useful adjunct to current therapeutic measures. J Atheroscler Thromb, 2004; 11: 49-55.
\end{abstract}

Key words: Cholesterol, Coronary artery disease, Crocetin, Total protein

\section{Introduction}

There has long been evidence that the amount of oxygen arriving at the artery wall has an important influence on whether or not the artery becomes and remains atherosclerotic. For example, in the cholesterol-fed rabbit, systemic hypoxia accelerates atherogenesis, while systemic hyperoxia both slows atherogenesis and, when combined with a return to a normal diet, reverses already established atherosclerotic lesions (1-3). In human patients with refractory ischemic ulcers who are treated with intra-arterial infusions of dilute hydrogen peroxide, the infused artery segment distal to the site of infusion has fewer and less severe atheromatous plaques than the

Address for correspondence: Louis Wm. Morgan, Cardiology Service, Letterman Army Medical Center, Presidio of San Francisco, P.O. Box 170582, San Francisco, CA 94117-0582, USA.

E-mail: loumorgan@earthlink.net

Received August 14, 2003.

Accepted for publication December 24, 2003. proximal, uninfused segment (4).

The two factors which determine how much oxygen is delivered to the artery wall are the partial pressure of the oxygen carried by the arterial hemoglobin $\left(\mathrm{PaO}_{2}\right)$ and the transport of this oxygen from the red corpuscles to the artery wall. It is this second factor, the delivery of oxygen from hemoglobin to the artery wall, which is the focus of this paper.

The artery wall is oxygenated from both the vasa vasorum and the arterial lumen, but the inner third receives most of its oxygen from the lumen $(3,5,6)$. Oxygen supplied by the lumen to the artery must cross two layers of plasma which are stationary in the direction in which the oxygen is moving. The first layer surrounds each erythrocyte, and the second is at the artery wall.

The red blood cells seem to be entrained in the plasma such that each is surrounded by a layer which is stationary relative its surface. Even under the extremely turbulent conditions produced in the stopped-flow apparatus used to make the measurement, only a small part of the 
resistance to transport of oxygen to or from erythrocytes is due to the red cell membrane; at least $70 \%$ is due to the enveloping layer of blood plasma (7-9).

Turbulence, however, is unusual in the circulatory system. Throughout most of its length, blood flow is laminar, with all points in the flow moving parallel to the vessel wall. The exceptions are at the upper end of the inferior vena cava, near bifurcations or valves, in the vicinity of large plaques which protrude into the lumen, and at the center of the thoracic aorta during peak systole. In all other arteries, the blood is stationary in the direction perpendicular to the vessel wall (10).

Although the reasons are still a matter of debate, hematocrit diminishes near the vessel wall. There are almost no red blood cells within the first 2-5 $\mu \mathrm{m}$, and cell density remains reduced $15 \mu \mathrm{m}$ into the lumen $(10,11)$. This reduction in cell density increases the effective distance that oxygen must travel to reach the artery wall, and it has been estimated that a $3 \mu \mathrm{m}$ layer of plasma doubles the resistance of a red blood cell to oxygen transport (12).

In order for oxygen to cross these two layers of blood plasma which are stationary in the direction in which the oxygen is moving, it must first dissolve in and then diffuse through the plasma. This combination of solubility and diffusivity has been called "permeability" by some authors and "transmissibility" by others. Since the term "permeability" has historical precedence and has been used more frequently, it will be used here. Permeability, then, is the algebraic product of the solubility of a solute in a solution times the diffusivity of the solute through the solution.

$$
\begin{aligned}
P=S \times & D \\
\text { where: } & P=\text { permeability } \\
& S=\text { solubility } \\
D & =\text { diffusivity. }
\end{aligned}
$$

The Bunsen solubility coefficients for oxygen $\left(\mathrm{O}_{2} \mathrm{~S}\right)$ in water and blood plasma at $37^{\circ} \mathrm{C}$ and $760 \mathrm{mmHg}$ have been reported to be:

$$
\begin{aligned}
& \mathrm{O}_{2} \mathrm{~S} \text { (water) }=2.39 \times 10^{-2} \mathrm{~cm}^{3}\left(\mathrm{O}_{2}\right) / \mathrm{cm}^{3} \text { (water) and } \\
& \mathrm{O}_{2} \mathrm{~S} \text { (plasma) }=2.14 \times 10^{-2} \mathrm{~cm}^{3}\left(\mathrm{O}_{2}\right) / \mathrm{cm}^{3} \text { (plasma), } \\
& \text { respectively (13). }
\end{aligned}
$$

The diffusivity of solutes such as oxygen through polymeric solutions such as blood plasma depends on the size, shape, weight and concentration of the dissolved polymers. Diffusion is impeded more by heavy molecules with large cross sections than by light molecules that are long and thin (14). In small concentrations, molecules that are very long and thin, such as crocetin, the carotenoid pigment in saffron, can even increase diffusivity (15).

The diffusivities of oxygen $\left(\mathrm{O}_{2} \mathrm{D}\right)$ through water and blood plasma have been measured at room temperature and normalized to $25^{\circ} \mathrm{C}$ using a correction factor of $2.5 \% /$ ${ }^{\circ} \mathrm{C}$ (16). The results were:

$$
\begin{aligned}
& \mathrm{O}_{2} \mathrm{D}(\text { water })=2.11 \times 10^{-5} \mathrm{~cm}^{2} / \mathrm{s} . \\
& \mathrm{O}_{2} \mathrm{D}(\text { plasma })=1.62 \times 10^{-5} \mathrm{~cm}^{2} / \mathrm{s} .
\end{aligned}
$$

Since the correction factor of $2.5 \% /{ }^{\circ} \mathrm{C}$ must be compounded every degree, the correction factor for a difference of $+12^{\circ} \mathrm{C}$ is not $30 \%$ but $34.5 \%$, and the values obtained at $25^{\circ} \mathrm{C}$ must be multiplied by 1.345 to estimate what they would have been at $37^{\circ} \mathrm{C}$. The resulting approximation is:

$$
\begin{aligned}
& \mathrm{O}_{2} \mathrm{D}(\text { water })=2.84 \times 10^{-5} \mathrm{~cm}^{2} / \mathrm{s} . \\
& \mathrm{O}_{2} \mathrm{D}(\text { plasma })=2.18 \times 10^{-5} \mathrm{~cm}^{2} / \mathrm{s} .
\end{aligned}
$$

The previously reported values for the solubilities of oxygen $\left(\mathrm{O}_{2} \mathrm{~S}\right)$ in and the diffusivities of oxygen $\left(\mathrm{O}_{2} \mathrm{D}\right)$ through water and blood plasma allow us to calculate estimates for the permeabilities $\left(\mathrm{O}_{2} \mathrm{P}\right)$ of water and blood plasma to oxygen at $37^{\circ} \mathrm{C}$ and $760 \mathrm{mmHg}$. Since $\mathrm{O}_{2} \mathrm{P}=$ $\mathrm{O}_{2} \mathrm{~S} \times \mathrm{O}_{2} \mathrm{D}$, these estimates are:

$$
\begin{aligned}
& \mathrm{O}_{2} \mathrm{P}(\text { water })=6.79 \times 10^{-7} \mathrm{~cm}^{2} / \mathrm{s} . \\
& \mathrm{O}_{2} \mathrm{P}(\text { plasma })=4.67 \times 10^{-7} \mathrm{~cm}^{2} / \mathrm{s} .
\end{aligned}
$$

\section{Subjects}

The study group consisted of thirty-eight cardiology inpatients at Letterman Army Medical Center (LAMC). Their ages ranged from 28 to 73 . Eight were females, and 30 were males. Informed consent was obtained from all subjects, and the study was reviewed and approved by the Institutional Review Committee of the LAMC Department of Clinical Investigation in accordance with the principles outlined in the Declaration of Helsinki.

\section{Methods}

The patients were assigned an active coronary artery disease score (ACAD- $x, x=0$ to 6 ) according to the scale presented in Table 1. Since we were measuring a parameter which we thought might be involved in active atherogenesis, we needed to distinguish between patients with actively progressing disease and patients who had obstructive lesions from past atherogenesis but whose disease process was not currently active. We, therefore, constructed a scale which is based both on the patients' current cardiac catheterization (cath) and on their past medical history, including any prior cardiac cath.

The lesions identified by the cardiac cath were judged according to how much myocardium they put at risk. This in turn depended on their location and on how much of 
the lumen they occluded. Lesions which occluded more than $50 \%$ of the lumen were generally considered to be obstructive and to endanger the myocardium in their distribution, unless the lumen was unusually large, in which case an occlusion of somewhat more than $50 \%$ might still be considered nonobstructive. Obstructive lesions of the major coronary arteries: i.e., the left main, left anterior descending, the left circumflex or the right coronary artery, were considered to endanger large areas of myocardium. Obstruction of minor arteries, such as an obtuse marginal branch, a diagonal branch or a posterior descending artery, were considered to endanger smaller areas of myocardium.

We accepted the date of the first cardiac cath as the date of reference, since it marked the time when the patient's disease became sufficiently symptomatic to require invasive intervention. On this basis, both patients undergoing their first cath who were found to have obstructive disease and patients with obstructive disease at cath less than two years ago with progression at the current cath were assumed to have the most active disease process and were given an active coronary artery disease score of ACAD-6. Patients with cath-identified obstruction less than two years ago but without progression at the present cath were considered to be the group with the next most active disease process and were given an active coronary artery disease score of ACAD-5. If patients had cath-proven obstruction more than two years ago which showed progression at the present cath, they were judged to have disease that was progressing, but more slowly than patients whose first cath was less than two years ago, and they were given an active coro-

Table 1. Active coronary artery disease score (ACAD- $x$ ).

\begin{tabular}{|c|c|}
\hline ACAD- $x$ & Criteria \\
\hline $\mathrm{ACAD}-0=$ & No detectable to very little disease $(<20 \%)$ \\
\hline ACAD-1 = & Non-obstructive disease (20-50\%) \\
\hline ACAD-2 = & Obstruction of minor arteries only \\
\hline ACAD-3 = & $\begin{array}{l}\text { Obstructive disease ( }>50 \%) \text { more than } 2 \text { years } \\
\text { ago without progression at current cath }\end{array}$ \\
\hline ACAD-4 = & $\begin{array}{l}\text { Obstructive disease ( }>50 \% \text { ) more than } 2 \text { years } \\
\text { ago with progression at current cath }\end{array}$ \\
\hline $\mathrm{ACAD}-5=$ & $\begin{array}{l}\text { Obstructive disease ( }>50 \% \text { ) less than } 2 \text { years } \\
\text { ago without further progression at current } \\
\text { cath }\end{array}$ \\
\hline ACAD-6 = & $\begin{array}{l}\text { Obstructive disease ( }>50 \% \text { ), either new or less } \\
\text { than } 2 \text { years ago with further progression at } \\
\text { current cath }\end{array}$ \\
\hline
\end{tabular}

ACAD- $x(x=0$ to 6$)$, active coronary artery disease score based both on the patient's current cardiac cath and on their past medical history. The percentages given in parentheses indicate the percentage of the lumen that was occluded. nary artery disease score of ACAD-4. Patients with cathproven obstruction more than two years ago but without progression at the current cath were assigned an active coronary artery disease score of ACAD-3. Patients whose only obstruction was in a minor artery were given an active coronary artery disease score of ACAD-2. Patients with only nonobstructive disease were assigned an active coronary artery disease score of ACAD-1, and patients with no detectable to very little disease were given an active coronary artery disease score of ACAD-0.

The permeability samples were obtained from the femoral artery during cardiac catheterization. This avoided changes in plasma composition resulting from venous compression (17). The plasma oxygen permeabilities $\left(\mathrm{O}_{2} \mathrm{P}\right)$ were measured at $37^{\circ} \mathrm{C}$ and $760 \mathrm{mmHg}$ using a steady-state method first described by Keller (18), and subsequently modified by Stein (19) and Morgan (20).

The total cholesterol (Chol), triglyceride (Tri) and total protein (TPro) values were obtained from the standard laboratory tests.

All statistical calculations were made using SPSS Graduate Pack 10.0 for Windows ${ }^{\circledR}$. The data were analyzed using three different methodologies: Student's $t$ Test, Pearson's product-moment correlation and linear regression.

In order to use Student's $t$-Test to look for differences associated with both active and all obstructive coronary artery disease, we divided our patients into two groups in two different ways, based on their active coronary artery disease (ACAD- $x$ ) scores. To look for differences associated with active coronary artery disease, we made the division between ACAD-3 and ACAD-4. Therefore, patients with scores between ACAD- 0 and ACAD- 3 were grouped together as not having actively progressing coronary artery disease, and patients with scores between ACAD- 4 and ACAD- 6 were grouped together as having coronary artery disease which was actively progressing. In a similar manner, we looked for differences associated with obstructive, but not necessarily active, coronary artery disease by making the division between ACAD-2 and ACAD-3. With this division, patients with scores between ACAD-0 and ACAD-2 were grouped together as not having clinically significant obstructive coronary artery disease, and patients with scores between ACAD- 3 and ACAD- 6 were grouped together as having obstructive coronary artery disease which was clinically significant. Student's $t$-Test was used to compare the means of the observed parameters for both of these divisions of our patients into two groups.

Pearson's product-moment correlations were calculated for all the data we obtained.

Two linear regression analyses were made with $A C A D$ $x$ as the dependent variable. The first analysis used $\mathrm{O}_{2} \mathrm{P}$, Chol, Tri, TPro and Age as the independent variables. The second analysis combined these five parameters into 
just two independent variables.

As discussed in the next section, we found significant multicollinearity among the variables. In order to diminish the statistical ambiguity introduced by the data multicollinearity, the first regression analysis was reformulated by combining the predictor variables. The first combined predictor variable was permeability divided by the sum of cholesterol and triglyceride $\left(\mathrm{O}_{2} \mathrm{P} /(\mathrm{Chol}+\mathrm{Tri})\right)$, and the second combined predictor variable was total protein divided by age (TPro / Age). This yielded the second linear regression analysis which was calculated using these combined variables. Combining collinear predictor variables in order to reduce the effects of multicollinearity on a regression analysis is an established statistical procedure (21-25).

In linear regression analyses, the beta values are regression equation coefficients which have been "standardized" so that the regression line passes through the origin and all values fall between 0 and \pm 1 . Adjusted Rsquared estimates how well the model fits the data. Variance inflation factor (VIF) is a measure of the collinearity of each individual parameter, and condition index is a measure of the multicollinearity of the entire model. A condition index of around 10 indicates multicollinearity which, although weak, may be starting to affect regression estimates. Condition indices of 30 to 100 indicate moderate to strong multicollinearity and indices of larger than 100 indicate serious multicollinearity problems (26).

\section{Results}

All of the data used in the statistical analysis of the relationship between plasma oxygen permeability and active coronary artery disease are given in Table 2.

The mean plasma oxygen permeability $\left(\mathrm{O}_{2} \mathrm{P}\right)$ was $5.25 \times 10^{-7} \mathrm{~cm}^{2} / \mathrm{s} \pm 0.5 \%$.

Twelve measurements of the permeability of ordinary tap water to oxygen at $37^{\circ} \mathrm{C}$ and $760 \mathrm{mmHg}$ were also made. The mean was $6.56 \times 10^{-7} \mathrm{~cm}^{2} / \mathrm{s} \pm 0.7 \%$.

Table 3 presents the results of using Student's $t$-Test to compare the means of the observed parameters for the group of patients who did and the group of patients who did not have actively progressing coronary artery disease. All significance levels $(p)$ are 2-tailed, and every $p<0.05$ indicates that the difference is significant. Therefore, there were statistically significant differences between the two groups in the means of three of the parameters we measured: $\mathrm{O}_{2} \mathrm{P}$, Chol and TPro.

Table 4 presents the results of using Student's $t$-Test to compare the means of the observed parameters for the group of patients who did and the group of patients who did not have clinically significant obstructive coronary artery disease, regardless of whether or not the disease was considered to be actively progressing. All significance levels $(p)$ are 2-tailed, and every $p<0.05$ indi-
Table 2. Patient data.

\begin{tabular}{|c|c|c|c|c|c|c|}
\hline Patient & $\begin{array}{c}\text { Age } \\
\text { (years) }\end{array}$ & $\begin{array}{c}\text { ACAD- } x \\
(x=0 \text { to } 6)\end{array}$ & $\begin{array}{c}\mathrm{O}_{2} \mathrm{P} \\
\left(10^{-7} \mathrm{~cm}^{2} / \mathrm{s}\right)\end{array}$ & $\begin{array}{c}\text { Chol } \\
(\mathrm{mg} / \mathrm{dl})\end{array}$ & $\begin{array}{c}\text { Tri } \\
\text { (mg/dl) }\end{array}$ & $\begin{array}{l}\text { TPro } \\
\text { (g/dl) }\end{array}$ \\
\hline 1 & 57 & ACAD-6 & 5.52 & 234 & 68 & 6.5 \\
\hline 2 & 72 & ACAD-6 & 5.39 & 272 & - & - \\
\hline 3 & 43 & ACAD-0 & 5.42 & 208 & 130 & 7.9 \\
\hline 4 & 57 & ACAD-6 & 5.18 & - & - & - \\
\hline 5 & 37 & ACAD-3 & 5.24 & 189 & - & 7.6 \\
\hline 6 & 73 & ACAD-6 & 5.26 & 186 & 66 & 6.2 \\
\hline 7 & 62 & ACAD-4 & 5.37 & - & - & - \\
\hline 8 & 45 & ACAD-6 & 5.04 & - & - & - \\
\hline 9 & 69 & ACAD-3 & 5.37 & 205 & 121 & - \\
\hline 10 & 50 & ACAD-5 & 5.05 & 273 & 451 & 6.8 \\
\hline 11 & 73 & ACAD-4 & 5.24 & 197 & 156 & - \\
\hline 12 & 40 & ACAD-6 & 5.39 & - & - & - \\
\hline 13 & 66 & ACAD-6 & 5.26 & 217 & 155 & 6.7 \\
\hline 14 & 73 & ACAD-4 & 4.94 & 162 & 167 & 5.4 \\
\hline 15 & 42 & ACAD-6 & 4.95 & - & - & 6.2 \\
\hline 16 & 49 & ACAD-0 & 5.26 & 162 & 85 & 8.3 \\
\hline 17 & 28 & ACAD-0 & 5.52 & 163 & 133 & 6.7 \\
\hline 18 & 76 & ACAD-1 & 5.40 & 160 & 97 & 6.4 \\
\hline 19 & 61 & ACAD-3 & 5.40 & 231 & 121 & 6.9 \\
\hline 20 & 51 & ACAD-1 & 5.43 & - & - & - \\
\hline 21 & 28 & ACAD-0 & 5.38 & - & - & - \\
\hline 22 & 73 & ACAD-1 & 5.58 & 153 & 80 & 6.7 \\
\hline 23 & 62 & ACAD-2 & 5.42 & - & - & - \\
\hline 24 & 56 & ACAD-0 & 5.34 & - & - & - \\
\hline 25 & 43 & ACAD-6 & 5.17 & 280 & 175 & 5.7 \\
\hline 26 & 66 & ACAD-4 & 5.04 & 251 & 172 & 6.7 \\
\hline 27 & 68 & ACAD-6 & 5.07 & 266 & 281 & 7.2 \\
\hline 28 & 55 & ACAD-4 & 4.99 & 532 & 1225 & 7.1 \\
\hline 29 & 66 & ACAD-0 & 5.15 & 182 & 103 & 6.6 \\
\hline 30 & 60 & ACAD-6 & 5.25 & 224 & 280 & 6.5 \\
\hline 31 & 63 & ACAD-1 & 5.03 & 197 & 101 & 6.6 \\
\hline 32 & 62 & ACAD-6 & 5.23 & 325 & 336 & 6.7 \\
\hline 33 & 53 & ACAD-1 & 5.30 & 193 & 122 & 6.4 \\
\hline 34 & 30 & ACAD-0 & 5.33 & 230 & 114 & 6.9 \\
\hline 35 & 59 & ACAD-1 & 5.12 & 223 & 321 & 7.6 \\
\hline 36 & 71 & ACAD-4 & 5.23 & 195 & 138 & 6.6 \\
\hline 37 & 69 & ACAD-3 & 5.15 & 234 & 152 & 6.6 \\
\hline 38 & 64 & ACAD-6 & 5.25 & 234 & 441 & 6.5 \\
\hline
\end{tabular}

"-" = data that was not available.

ACAD- $x$ : active coronary artery disease score, $\mathrm{O}_{2} \mathrm{P}$ : plasma oxygen permeability, Chol: serum cholesterol, Tri: serum triglyceride, TPro: serum total protein, $1 \mathrm{dl}=100 \mathrm{ml}$. 
Table 3. Active coronary artery disease $t$-test for equality of means.

\begin{tabular}{llllllll}
\hline Parameter & ACAD- $x$ range & $N$ & Mean & Diff. & $t$ & df & $p$ \\
\hline $\begin{array}{l}\mathrm{O}_{2} \mathrm{P} \\
\left(10^{-7} \mathrm{~cm}^{2} / \mathrm{s}\right)\end{array}$ & ACAD-0 to 3 & 18 & 5.32 & 0.13 & 2.70 & 36 & 0.011 \\
& ACAD-4 to 6 & 20 & 5.19 & & & & \\
Chol & ACAD-0 to 3 & 14 & 195 & 62 & 2.52 & 27 & 0.018 \\
$(\mathrm{mg} / \mathrm{dl})$ & ACAD-4 to 6 & 15 & 257 & & & & \\
& & & & & & & \\
Tri & ACAD-0 to 3 & 13 & 129 & 164 & 1.97 & 25 & 0.060 \\
$(\mathrm{mg} / \mathrm{dl})$ & ACAD-4 to 6 & 14 & 294 & & & & \\
& & & & & & & \\
TPro & ACAD-0 to 3 & 13 & 7.02 & 0.53 & 2.48 & 25 & 0.020 \\
$(\mathrm{~g} / \mathrm{dl})$ & ACAD-4 to 6 & 14 & 6.49 & & & & \\
& & & & & & & \\
Age & ACAD-0 to 3 & 18 & 54.1 & 5.9 & 1.37 & 36 & 0.180 \\
(years) & ACAD-4 to 6 & 20 & 60.0 & & & & \\
\hline
\end{tabular}

ACAD- $x$ Range: range of the active coronary artery disease scores which define the two groups being compared, $N$ : number of patients in the two groups, Mean: mean of the relevant parameter for each of the two groups, Diff.: difference between the means of the parameters, $t$ : Student's $t$ for the difference of the means, df: degree of freedom for $t, p$ : 2-tailed probability that the difference between the means is due to chance, $\mathrm{O}_{2} \mathrm{P}$ : plasma oxygen permeability, Chol: serum cholesterol, Tri: serum triglyceride, TPro: serum total protein, $1 \mathrm{dl}=100 \mathrm{ml}$.

Table 4. Obstructive coronary artery disease $t$-test for equality of means.

\begin{tabular}{llllllll}
\hline Parameter & ACAD- $x$ range & $N$ & Mean & Diff. & $t$ & df & $p$ \\
\hline $\begin{array}{l}\mathrm{O}_{2} \mathrm{P} \\
\left(10^{-7} \mathrm{~cm}^{2} / \mathrm{s}\right)\end{array}$ & ACAD-0 to 2 & 14 & 5.33 & 0.12 & 2.47 & 36 & 0.018 \\
& ACAD-3 to 6 & 24 & 5.21 & & & & \\
Chol & ACAD-0 to 2 & 10 & 187 & 61 & 2.33 & 27 & 0.028 \\
$(\mathrm{mg} / \mathrm{dl})$ & ACAD-3 to 6 & 19 & 248 & & & & \\
& & & & & & & \\
$\mathrm{Tri}$ & $\mathrm{ACAD}-0$ to 2 & 10 & 129 & 136 & 1.54 & 25 & 0.136 \\
$(\mathrm{mg} / \mathrm{dl})$ & ACAD-3 to 6 & 17 & 265 & & & & \\
& & & & & & & \\
TPro & ACAD-0 to 2 & 10 & 7.01 & 0.43 & 1.85 & 25 & 0.077 \\
$(\mathrm{~g} / \mathrm{dl})$ & ACAD-3 to 6 & 17 & 6.58 & & & & \\
& & & & & & & \\
Age & ACAD-0 to 2 & 14 & 52.6 & 7.4 & 1.62 & 36 & 0.115 \\
(years) & ACAD-3 to 6 & 24 & 60.0 & & & & \\
\hline
\end{tabular}

ACAD- $x$ Range: range of the active coronary artery disease scores which define the two groups being compared, $N$ : number of patients in the two groups, Mean: mean of the relevant parameter for each of the two groups, Diff.: difference between the means of the parameters, $t$ : Student's $t$ for the difference of the means, df: degree of freedom for $t, p$ : 2-tailed probability that the difference between the means is due to chance, $\mathrm{O}_{2} \mathrm{P}$ : plasma oxygen permeability, Chol: serum cholesterol, Tri: serum triglyceride, TPro: serum total protein, $1 \mathrm{dl}=100 \mathrm{ml}$ cates that the difference is significant. Therefore, there were statistically significant differences between the two groups in the means of two of the parameters we measured: $\mathrm{O}_{2} \mathrm{P}$ and Chol. With this division, the difference in the mean TPro of the two groups was not significant.

Table 5 presents the matrix of Pearson product-moment correlation coefficients and their significance for the data given in Table 2. As above, all significance levels $(p)$ are 2-tailed, and every $p<0.05$ indicates that the correlation is significant. As can be seen, ACAD- $x$ has significant correlations with $\mathrm{O}_{2} \mathrm{P}$, Chol, and TPro; $\mathrm{O}_{2} \mathrm{P}$ has additional significant correlations with $\mathrm{Chol}$ and $\mathrm{Tri}$, and Chol has an additional significant correlation with Tri. This network of interlocking significant correlations is called multicollinearity.

The results of the linear regression analysis with $A C A D-$ $x$ as the dependent variable and using $\mathrm{O}_{2} \mathrm{P}$, Chol, Tri, TPro and age as the independent variables are presented in the coefficient matrix below. As can be seen, the resulting model and one of the beta coefficients were statistically significant, but the condition index was unacceptably high. This is a typical consequence of data multicollinearity (26).

\begin{tabular}{|c|c|c|c|}
\hline Parameter & Beta & $p$ & VIF \\
\hline (Constant) & 0.000 & 0.194 & - \\
\hline $\mathrm{O}_{2} \mathrm{P}$ & -0.159 & 0.416 & 1.383 \\
\hline Chol & 0.856 & 0.034 & 5.271 \\
\hline Tri & -0.376 & 0.374 & 5.639 \\
\hline TPro & -0.354 & 0.082 & 1.219 \\
\hline Age & 0.150 & 0.425 & 1.118 \\
\hline \multicolumn{4}{|c|}{$\begin{array}{ll}\text { adjusted } R \text {-squared } & =0.27 \\
\text { condition index } & =124\end{array}$} \\
\hline
\end{tabular}

When a linear regression analysis was made with ACAD$x$ as the dependent variable but with combined predictor variables replacing the individual predictor variables, all beta coefficients were statistically significant, the significance of the model, the adjusted $R$-squared, and the VIF's all improved, and the condition index fell to within the acceptable range.

\begin{tabular}{|c|c|c|c|}
\hline Parameter & Beta & $p$ & VIF \\
\hline (Constant) & 0.000 & 0.000 & - \\
\hline $\mathrm{O}_{2} \mathrm{P} /(\mathrm{Chol}+\mathrm{Tri})$ & -0.494 & 0.006 & 1.002 \\
\hline TPro / Age & -0.400 & 0.022 & 1.002 \\
\hline \multicolumn{4}{|c|}{$\begin{array}{ll}p(\text { significance of model }) & =0.002 \\
\text { adjusted } R \text {-squared } & =0.37 \\
\text { condition index } & =9\end{array}$} \\
\hline
\end{tabular}




\section{Discussion}

The permeabilities of water and blood plasma to oxygen that were measured at $37^{\circ} \mathrm{C}$ and $760 \mathrm{mmHg}$ in the present study are within the same general range as the estimates for $37^{\circ} \mathrm{C}$ calculated from the previously reported diffusivity measurements that were made at $25^{\circ} \mathrm{C}$. The differences probably reflect the very approximate nature of the $2.5 \% /{ }^{\circ} \mathrm{C}$ correction factor used in calculating the $37^{\circ} \mathrm{C}$ estimates.

We designed our coronary artery disease scale to maximize our ability to identify those factors which are associated with the active progression of coronary artery disease. As it turned out, the factors associated with the active progression of coronary artery disease are very similar to the factors associated with the presence of clinically significant coronary artery disease without regard to whether the disease is actively progressing or not. Perhaps this should not have been a surprise in light of the Framingham study which found great stability in the physiological parameters of their patients over a span of 30 years $(27,28)$.

Although analysis of our data by both Student's $t$-Test and Pearson's product moment correlation suggests a role for $\mathrm{O}_{2} \mathrm{P}$ in atherogenesis, the multicollinearity of the data makes it difficult to separate the effects of the collinear variables. When Chol goes up, $\mathrm{O}_{2} \mathrm{P}$ goes down. Are the consequences due to increased Chol, decreased $\mathrm{O}_{2} \mathrm{P}$, or both? A better understanding of the relationship between plasma oxygen permeability and atherogenesis might be gained by an experiment which manipulates $\mathrm{O}_{2} \mathrm{P}$ under controlled conditions.

As has already been mentioned, crocetin enhances the diffusivity factor of permeability, and it has been shown, in cholesterol-fed rabbits, that crocetin reduces atherogenesis (29-32). This is the first study to find a relationship in humans between coronary artery disease and the permeability of oxygen through blood plasma. Should additional studies confirm these initial results, they would suggest that increasing a patient's plasma oxygen permeability by treatment with substances such as crocetin might serve as a helpful adjunct to current therapies which focus on lowering a patient's cholesterol levels.

Acknowledgment: Financial support for the development and construction of the permeability meter used in this research was provided by Dean and Emalou Morgan, the parents of one of the investigators.

Notice of grant support: No grants or other institutional support were received.

\section{References}

(1) Kudchodkar BJ, Wilson J, Lacko A, and Dory L: Hyperbaric oxygen reduces the progression and accelerates the regression of atherosclerosis in rabbits. Arterioscler Thromb Vasc Biol, 20: 1637-1643, 2000

( 2 ) Gainer JL: Hypoxia and atherosclerosis: re-evaluation of an old hypothesis. Atherosclerosis, 68: 263266, 1987

(3) Goldstick TK and Dobrin PB: Arterial wall oxygen transport and its relationship to atherogenesis. In: Handbook of Bioengineering. ed by Skalak R and Chien S, pp 22.1-22.11, McGraw-Hill Books, New York, 1987

( 4 ) Finney JW, Lynn JA, Jay BE, Urschel HC, Balla GA,

Table 5. Correlation coefficients and their significance.

\begin{tabular}{|c|c|c|c|c|c|c|}
\hline Parameter & $\begin{array}{c}\text { ACAD- } x \\
(x=0 \text { to } 6)\end{array}$ & $\begin{array}{c}\mathrm{O}_{2} \mathrm{P} \\
\left(10^{-7} \mathrm{~cm}^{2} / \mathrm{s}\right)\end{array}$ & $\begin{array}{c}\text { Chol } \\
\text { (mg/dl) }\end{array}$ & $\begin{array}{c}\text { Tri } \\
(\mathrm{mg} / \mathrm{dl})\end{array}$ & $\begin{array}{l}\text { TPro } \\
\text { (g/dl) }\end{array}$ & $\begin{array}{l}\text { Age } \\
\text { (years) }\end{array}$ \\
\hline ACAD $-x(x=0$ to 6$)$ & 1.000 & & & & & \\
\hline $\begin{array}{c}\mathrm{O}_{2} \mathrm{P}\left(10^{-7} \mathrm{~cm}^{2} / \mathrm{s}\right) \\
p=0.039\end{array}$ & -0.336 & 1.000 & & & & \\
\hline $\begin{array}{r}\text { Chol }(\mathrm{mg} / \mathrm{dl}) \\
\quad p=0.032\end{array}$ & 0.398 & $\begin{array}{r}-0.380 \\
0.042\end{array}$ & 1.000 & & & \\
\hline $\begin{array}{l}\text { Tri (mg/dl) } \\
\qquad p=0.177\end{array}$ & 0.267 & $\begin{array}{r}-0.449 \\
0.019\end{array}$ & $\begin{array}{l}0.893 \\
0.000\end{array}$ & 1.000 & & \\
\hline $\begin{array}{l}\text { TPro (g/dl) } \\
\qquad p=0.024\end{array}$ & -0.433 & $\begin{array}{l}0.190 \\
0.341\end{array}$ & $\begin{array}{l}0.064 \\
0.757\end{array}$ & $\begin{array}{l}0.133 \\
0.526\end{array}$ & 1.000 & \\
\hline $\begin{array}{l}\text { Age (years) } \\
\qquad p=0.136\end{array}$ & 0.246 & $\begin{array}{r}-0.110 \\
0.513\end{array}$ & $\begin{array}{r}-0.086 \\
0.658\end{array}$ & $\begin{array}{r}-0.086 \\
0.670\end{array}$ & $\begin{array}{r}-0.307 \\
0.120\end{array}$ & 1.000 \\
\hline
\end{tabular}

ACAD- $x$ : active coronary artery disease score, $\mathrm{O}_{2} \mathrm{P}$ : plasma oxygen permeability, Chol: serum cholesterol, Tri: serum triglyceride, TPro: serum total protein, $1 \mathrm{dl}=100 \mathrm{ml}, p$ : 2-tailed probability that the correlation is due to chance. 
and Race GJ: Treatment of refractory ischemic ulcers in humans by regional hyperoxia (intra-arterial $\mathrm{H}_{2} \mathrm{O}_{2}$ ). In: Proceedings of the Fourth International Conference on Hyperbaric Medicine. ed by Wada J and Iwa T, pp 472-477, Williams \& Wilkins, Baltimore, 1969

( 5 ) Santilli SM, Kronson J, and Payne WD: The effect of hypercholesterolemia on the rabbit transarterial wall oxygen gradient. Ann Vasc Surg, 12: 418-423, 1998

( 6 ) Niinikoski J, Heughan C, and Hunt TK: Oxygen tensions in the aortic wall of normal rabbits. Atherosclerosis, 17: 353-359, 1973

( 7 ) Huxley VH and Kutchai $\mathrm{H}$ : The effect of the red cell membrane and a diffusion boundary layer on the rate of oxygen uptake by human erythrocytes. $J$ Physiol, 316: 75-83, 1981

( 8 ) Huxley VH and Kutchai $\mathrm{H}$ : Effect of diffusion boundary layers on the initial uptake of $\mathrm{O}_{2}$ by red cells. Theory versus experiment. Microvascular Research, 26: 89-107, 1983

( 9 ) Holland RAB, Shibata H, Scheid P and Piiper J: Kinetics of $\mathrm{O}_{2}$ uptake and release by red cells in stopped-flow apparatus: effects of unstirred layer. Respir Physiol, 59: 71-91, 1985

(10) McDonald DA: Blood Flow in Arteries, pp 27-78, Williams and Wilkins, Baltimore, 1974

(11) Blackshear PL Jr, Forstrom RJ, Dorman FD and Voss GO: Effect of flow on cells near walls. Fed Proc, 30: 1600-1604, 1971

(12) Sinha AK: $\mathrm{O}_{2}$ uptake and release by red cells through plasma layer and capillary wall. Adv Exp Med Biol, 159: 525-537, 1983

(13) Altman PL and Dittmer DS: Respiration and Circulation, pp 16-18, Federation of American Societies for Experimental Biology, Bethesda, 1971

(14) Navari RM, Gainer JL, and Hall KR: A predictive theory for diffusion in polymer and protein solutions. American Institute of Chemical Engineers Journal, 17: 1028-1036, 1971

(15) Gainer JL and Brumgard FB: Using excess volume of mixing to correlate diffusivities in liquids. Chem Eng Commun, 15: 323-329, 1982

(16) Goldstick TK, Ciuryla VT, and Zuckerman L: Diffusion of oxygen in plasma and blood. In: Advances in Experimental Medicine and Biology 75 - Oxygen Transport to Tissue II. ed by Grote J, Reneau D, and Thews G, pp 183-190, Plenum Press, New York, 1976

(17) Statland BE, Bokelund H, and Winkel P: Factors contributing to intra-individual variation of serum constituents: 4. Effects of posture and tourniquet application on variation of serum constituents in healthy subjects. Clin Chem, 20: 1513-1519, 1974

(18) Keller KH and Friedlander SK: The steady-state transport of oxygen through hemoglobin solutions. J Gen Physiol, 49: 663-679, 1966

(19) Stein TR, Martin JC, and Keller KH: Steady-state oxygen transport through red blood cell suspensions. J Appl Physiol, 31: 397-402, 1971

(20) Morgan LW: Plasma oxygen permeability meter. US Patent \#4,539,092, 1985

(21) Kline RB: Principles and Practice of Structural Equation Modeling, p 78, The Guilford Press, New York, 1998

(22) McNeil K, Newman I, and Kelly JF: Testing Research Hypotheses with the General Linear Model, p 255, Southern Illinois University Press, Carbondale, 1996

(23) Mueller RO: Basic Principles of Structural Equation Modeling, p 22, Springer-Verlag, New York, 1996

(24) Jobson JD: Applied Multivariate Data Analysis, $p$ 285, Springer-Verlag, New York, 1991

(25) Wittink DR: The Application of Regression Analysis, pp 87-100, Allyn and Bacon, Boston, 1988

(26) Rawlings JO: Applied Regression Analysis. A Research Tool, pp 162-374, Wadsworth, Belmont, 1988

(27) The Framingham Study, Section 29, Means at each examination and inter-examination variation of specified characteristics: Exam 1 to Exam 10. National Institutes of Health, Department of Health, Education and Welfare, 1974

(28) The Framingham Study, Section 36, Means at each examination and inter-examination consistency of specified characteristics: 30 year follow-up. National Institutes of Health, Department of Health and Human Services, 1987

(29) Gainer JL and Chisolm GM: Mass transfer in atherosclerosis. In: Advances in Biomedical Engineering, Part II. ed by Cooney DO, pp 391-426, Marcel Dekker, New York, 1980

(30) Pool JD, Gainer JL and Chisolm GM: Oxygen diffusion and atherosclerosis. In: Advances in Experimental Medicine and Biology 67 - Atherosclerosis Drug Discovery. ed by Day CE, pp 205-211, Plenum Press, New York, 1976

(31) Gainer JL and Chisolm GM: Oxygen diffusion and atherosclerosis. Atherosclerosis, 19: 135-138, 1974

(32) Gainer JL: Process for increasing oxygen diffusivity. US Patent \#3,788,468, 1974 